\title{
Rank-Engel conditions on linear groups
}

\author{
B. A. F. Wehrfritz ${ }^{1}$
}

Received: 14 February 2019 / Accepted: 15 January 2020 / Published online: 29 January 2020

(c) The Author(s) 2020

\begin{abstract}
We study linear groups $\mathrm{G}$ for which for every $\mathrm{g}$ in $\mathrm{G}$ there exists a subgroup $\mathrm{E}$ of $\mathrm{G}$ satisfying some sort of rank condition and such that for every $\mathrm{x}$ in $\mathrm{G}$ there is a positive integer $\mathrm{m}$ such that for all $\mathrm{n} \geq \mathrm{m}$ the repeated commutator $\left[\mathrm{x},{ }_{\mathrm{n}} \mathrm{g}\right]$ lies in $\mathrm{E}$. If $\mathrm{E}$ can always be chosen to be a Chernikov group (resp. a polycyclic-by-finite group) such $\mathrm{G}$ can be completely described (Wehrfritz in Adv Group Theory Appl 7:143-157, 2019; Wehrfritz in Boll Unione Mat Ital, to appear). For more general rank conditions our analyses below are complete for positive characteristics but are less so for characteristic zero.
\end{abstract}

Keywords Engel conditions $\cdot$ Rank conditions $\cdot$ Linear group $\cdot$ Matrix group

Mathematics Subject Classification $20 \mathrm{~F} 45 \cdot 20 \mathrm{E} 34 \cdot 20 \mathrm{H} 20$

If $\mathrm{g}$ is an element and $\mathrm{H}$ a subgroup of a group $\mathrm{G}$, adapting slightly terminology from [8], call a subgroup $\mathrm{E}$ of $\mathrm{H}$ a sink for $\mathrm{g}$ (or a g-sink) in $\mathrm{H}$ if for each $\mathrm{h}$ in $\mathrm{H}$ there exists a positive integer $m(h)$ such that $\left[h,{ }_{n} g\right] \in E$ for all $n \geq m(h)$. If $\mathbf{X}$ is a class of groups, say that a group $\mathrm{G}$ is $\mathbf{X}$-Engel if every $\mathrm{g}$ in $\mathrm{G}$ has a sink in $\mathrm{G}$ belonging to $\mathbf{X}$.

There are many different rank conditions on groups, but by Lemma 1 below for linear groups, apart from the Chernikov groups and the polycyclic-by-finite groups, the only classes of interest for the Engel-type conditions here are just three (four in positive characteristic). Below $\mathbf{X}_{\mathrm{fr}}$ denotes the class of all groups of finite (Prüfer) rank, $\mathbf{X}_{\mathrm{ftr}}$ the class of all soluble-by-finite groups of finite abelian total rank (see below) and $\mathbf{X}_{\mathrm{mm}}$ the class of all minimax groups, i.e. poly (groups that satisfy the minimal-by-maximal condition). Also let $\mathbf{X}_{\mathrm{fh}}$ denote the class of all groups with finite Hirsch number; that is all groups $\mathrm{G}$ with a series of finite length each factor of which is either locally finite or infinite cyclic, the number of infinite cyclic factors in such a series being the Hirsch number $h(G)$ of $G$.

Further let $\mathbf{F}$ denote the class of finite groups, $\mathbf{C h}$ the class of Chernikov groups and $\mathbf{P}$ the class of polycyclic groups, so PF denotes the class of polycyclic-by-finite groups. Also LF denotes the class of locally finite groups; that is, the class of all groups $\mathrm{G}$ with $\mathrm{h}(\mathrm{G})=0$.)

B. A. F. Wehrfritz

b.a.f.wehrfritz@qmul.ac.uk

1 Queen Mary University of London, London E1 4NS, England, UK 
Let $\mathrm{G}$ be a linear group. A special case of Shumyatsky's main theorem in [8] says that $\mathrm{G}$ is F-Engel if and only if $\mathrm{G}$ is finite-by-hypercentral. By Theorem 1.2 of [14] $\mathrm{G}$ is $\mathbf{C h}$-Engel if and only if $\mathrm{G}$ is Chernikov-by-hypercentral and by Theorem 1.4 of [14] if $G$ has positive characteristic, then G is PF-Engel if and only if G is PF-byhypercentral. PF-Engel linear groups of characteristic zero are much more varied. They are completely characterized in [15]. Among the linear groups $\mathrm{G}$ of characteristic zero they are exactly the ones with a normal series $<1>=\mathrm{T}_{0} \leq \mathrm{T}_{1} \leq \cdots \leq \mathrm{T}_{\mathrm{s}}=\mathrm{T} \leq \mathrm{G}$ with $\mathrm{s}$ and the index $(\mathrm{G}: \mathrm{T})$ finite and each $\mathrm{T}_{\mathrm{i}} / \mathrm{T}_{\mathrm{i}-1}$ polycyclic-by-finite, or G-hypercentral with $\left[\mathrm{T}_{\mathrm{i}}\right.$, $\mathrm{T}] \leq \mathrm{T}_{\mathrm{i}-1}$, or G-hypercentral, abelian and Chernikov.

Theorem 1 Let $G$ be a subgroup of $\mathrm{GL}(\mathrm{n}, \mathrm{F})$, where $\mathrm{n}$ is a positive integer and $\mathrm{F}$ is a field of positive characteristic and let $\mathbf{X}$ be one of the five classes $\mathbf{X}_{\mathrm{fr}}, \mathbf{X}_{\mathrm{ftr}}, \mathbf{X}_{\mathrm{mm}}, \mathbf{X}_{\mathrm{fh}}$ and LF. Then $G$ is $\mathbf{X}$-Engel if and only if $\mathrm{G}$ has a normal $\mathbf{X}$-subgroup $\mathrm{N}$ such that $\mathrm{G} / \mathrm{N}$ is hypercentral.

$\mathbf{X}_{\mathrm{fr}}$ is the main case in Theorem 1, the other four cases can be thought of as corollaries of it or its proof. If the group $G$ is linear of characteristic zero, then $G \in \mathbf{X}_{\mathrm{fh}}$ if and only if $\mathrm{G} \in \mathbf{X}_{\mathrm{fr}}$, so $\mathrm{G}$ is $\mathbf{X}_{\mathrm{fh}}$-Engel if and only $\mathrm{G}$ is $\mathbf{X}_{\mathrm{fr}}$-Engel. Thus in characteristic zero we have really only three cases to consider.

Theorem 2 Let $\mathrm{G}$ be an $\mathbf{X}$-Engel subgroup of $\mathrm{GL}(\mathrm{n}, \mathrm{F})$, where $\mathrm{n}$ is a positive integer, $\mathrm{F}$ is a field of characteristic zero and $\mathbf{X}$ is $\mathbf{X}_{\mathrm{fr}}, \mathbf{X}_{\mathrm{ftr}}$ or $\mathbf{X}_{\mathrm{mm}}$. Then $\mathrm{G}$ has a normal series

$$
<1>=\mathrm{U}_{0} \leq \mathrm{V}_{1} \leq \mathrm{U}_{1} \leq \cdots \leq \mathrm{V}_{\mathrm{t}} \leq \mathrm{U}_{\mathrm{t}}=\mathrm{U} \leq \mathrm{T} \leq \mathrm{G}
$$

such that $\mathrm{t} \leq \mathrm{n}(\mathrm{n}-1) / 2, \mathrm{G} / \mathrm{T}$ is finite, $\mathrm{T} / \mathrm{U}$ is abelian, $\mathrm{U}$ is unipotent and for each $\mathrm{i}$ with $1 \leq \mathrm{i} \leq \mathrm{t},\left[\mathrm{U}_{\mathrm{i}}, \mathrm{U}\right] \leq \mathrm{U}_{\mathrm{i}-1}, \mathrm{U}_{\mathrm{i}} / \mathrm{U}_{\mathrm{i}-1}$ is torsion-free (abelian) and either $\mathrm{U}_{\mathrm{i}} / \mathrm{U}_{\mathrm{i}-1} \in \mathbf{X}$ with $\mathrm{V}_{\mathrm{i}}=\mathrm{U}_{\mathrm{i}}$, or $\left[\mathrm{U}_{\mathrm{i}}, \mathrm{T}\right] \leq \mathrm{U}_{\mathrm{i}-1}$ with $\mathrm{V}_{\mathrm{i}} / \mathrm{U}_{\mathrm{i}-1} \in \mathbf{X}$ and $\mathrm{U}_{\mathrm{i}} / \mathrm{V}_{\mathrm{i}} \mathrm{G}$-hypercentral. Also there is a normal subgroup $\mathrm{S}$ of $\mathrm{G}$ with $\mathrm{U} \leq \mathrm{S}, \mathrm{S} / \mathrm{U} \in \mathbf{X}_{\mathrm{fr}}$ (even $\mathrm{S} / \mathrm{U} \in \mathbf{X}_{\mathrm{mm}}$ if $\mathbf{X}=\mathbf{X}_{\mathrm{mm}}$ ) and $\mathrm{G} / \mathrm{S}$ hypercentral. Further if $\mathbf{X}=\mathbf{X}_{\mathrm{mm}}$ then each $\mathrm{T} / \mathrm{C}_{\mathrm{T}}\left(\mathrm{U}_{\mathrm{i}} / \mathrm{U}_{\mathrm{i}-1}\right)$ is finitely generated (and abelian).

Theorem 3 Let $\mathrm{G}$ be a connected (in the Zariski topology) subgroup of $\mathrm{GL}(\mathrm{n}, \mathrm{F})$, where $\mathrm{n}$ is a positive integer and $\mathrm{F}$ is a field of characteristic zero. If $\mathbf{X}$ is $\mathbf{X}_{\mathrm{fr}}, \mathbf{X}_{\mathrm{ftr}}$ or $\mathbf{X}_{\mathrm{mm}}$, then $\mathrm{G}$ is $\mathbf{X}$-Engel if and only if $\mathrm{G}$ has a normal series

$$
<1>=\mathrm{U}_{0} \leq \mathrm{U}_{1} \leq \cdots \leq \mathrm{U}_{\mathrm{t}}=\mathrm{U} \leq \mathrm{G},
$$

where $\mathrm{t}$ is finite, $\mathrm{G} / \mathrm{U}$ is abelian and for each $\mathrm{i}$ we have $\left[\mathrm{U}_{\mathrm{i}}, \mathrm{U}\right] \leq \mathrm{U}_{\mathrm{i}-1}$ and either $\mathrm{U}_{\mathrm{i}} /$ $\mathrm{U}_{\mathrm{i}-1} \in \mathbf{X}$ or $\left[\mathrm{U}_{\mathrm{i}}, \mathrm{G}\right] \leq \mathrm{U}_{\mathrm{i}-1}$.

Corollary Let $\mathrm{G}$ subgroup of $\mathrm{GL}(\mathrm{n}, \mathrm{F})$, where $\mathrm{n}$ is a positive integer and $\mathrm{F}$ is a field of characteristic zero and let $\mathbf{X}$ denote $\mathbf{X}_{\mathrm{fr}}, \mathbf{X}_{\mathrm{ftr}}$ or $\mathbf{X}_{\mathrm{mm}}$. Then $\mathrm{G}$ is a finite extension of an $\mathbf{X}$ Engel group if and only if $\mathrm{G}$ has a series

$$
<1>=\mathrm{U}_{0} \leq \mathrm{U}_{1} \leq \cdots \leq \mathrm{U}_{\mathrm{t}}=\mathrm{U} \leq \mathrm{T} \leq \mathrm{G},
$$

where $\mathrm{t}$ is finite, $\mathrm{G} / \mathrm{T}$ is finite, $\mathrm{T} / \mathrm{U}$ is abelian and for each $\mathrm{i}$ we have $\mathrm{U}_{\mathrm{i}}$ normal in $\mathrm{T},\left[\mathrm{U}_{\mathrm{i}}\right.$, $\mathrm{U}] \leq \mathrm{U}_{\mathrm{i}-1}$ and either $\mathrm{U}_{\mathrm{i}} / \mathrm{U}_{\mathrm{i}-1} \in \mathbf{X}$ or $\left[\mathrm{U}_{\mathrm{i}}, \mathrm{T}\right] \leq \mathrm{U}_{\mathrm{i}-1}$. 
The following simple result complements the LF case of Theorem 1. Its short proof does not depend on any of the theorems above.

Theorem 4 Let $\mathrm{G}$ subgroup of $\mathrm{GL}(\mathrm{n}, \mathrm{F})$, where $\mathrm{n}$ is a positive integer and $\mathrm{F}$ is a field of characteristic zero. Then $\mathrm{G}$ is $\mathrm{LF}$-Engel if and only if $\mathrm{G}$ is (locally finite)-by-hypercentral.

\section{General Lemmas}

Let $\mathrm{G}$ be a subgroup of GL(n, F), where $\mathrm{n}$ is a positive integer and $\mathrm{F}$ is a field of characteristic zero. Consider the following.

(a) G has finite Hirsch number $h(G)$.

(b) $\mathrm{G}$ is an FAR-group (cf. [5]); that is, $\mathrm{G}$ is soluble-by-finite with $\mathrm{h}(\mathrm{G})$ finite and satisfying min-q, the minimal condition on q-subgroups, for every prime $\mathrm{q}$.

(c) G has finite rank.

(d) $\mathrm{G}$ is an FATR-group (again cf. [5]); that is, G satisfies (b) and $\pi(\mathrm{G})=$ \{primes q : $\mathrm{G}$ has an element of order q $\}$ is finite.

(e) $\mathrm{G}$ is minimax.

Lemma $1 \mathrm{a}$ (char $\mathrm{F}=0)(\mathrm{a}),(\mathrm{b})$ and (c) are equivalent, (d) implies (c) and (e) implies (d). Now suppose $\mathrm{F}$ has characteristic $\mathrm{p}>0$ and consider the following further two conditions.

$\left(\mathrm{a}^{\prime}\right) \mathrm{h}(\mathrm{G})$ is finite and $\mathrm{G}$ satisfies min-p.

(c') $\mathrm{G}$ is abelian-by-finite and rankG is finite.

Lemma $1 \mathbf{b}$ (charF $>0)$. ( $\left(\mathrm{a}^{\prime}\right),(\mathrm{b}),(\mathrm{c})$ and $\left(\mathrm{c}^{\prime}\right)$ are equivalent, (d) implies (c) and (e) implies (d).

Thus for linear groups we are effectively reduced to just four rank classes to consider, namely those defined by (a), (c), (d) and (e); that is, the classes $\mathbf{X}_{\mathrm{fr}}, \mathbf{X}_{\mathrm{ftr}}, \mathbf{X}_{\mathrm{mm}}$ and in positive characteristic $\mathbf{X}_{\mathrm{fh}}$. Trivially ( $\mathrm{a}^{\prime}$ ) implies (a). We denote the maximum periodic normal subgroup of a group $\mathrm{G}$ by $\tau(\mathrm{G})$.

Proof Suppose charF $=0$. If $h(G)$ is finite, then $\mathrm{G} / \tau(\mathrm{G})$ has a poly(torsion-free abelian of finite rank) normal subgroup of finite index (e.g. [12] Lemma 4). Also G satisfies min-q for every prime $\mathrm{q}$ ([9] 9.1iv)) and $\tau(\mathrm{G})$ has an abelian normal subgroup of finite index and rank at most $\mathrm{n}$. Therefore (a) implies (b) and (c). Trivially (b) implies (a). If $\mathrm{G}$ has finite rank, the $G$ is soluble-by-finite by a theorem of Platonov ([9] 10.9). Thus (c) implies (a). Trivially (d) implies (b). Let G satisfy (e). Linear groups with the minimal condition are Chernikov ([9] 9.8) and linear groups with the maximal condition are polycyclic-by-finite (by a theorem of Tits, see [9] 10.18). Then [9] 5.11 and 6.4 yield that $\mathrm{G}$ is soluble-by-finite. Hence (e) implies (d).

Now assume charF $=p>0$. Suppose $G$ is periodic and satisfies min-p. Then the Sylow p-subgroups of $\mathrm{G}$ are finite and hence (see [9] 9.7) $\mathrm{G}$ is a finite extension of an abelian 
$\mathrm{p}^{\prime}$-subgroup of rank at most $\mathrm{n}$. Thus as in the proof of the characteristic zero case we obtain that $\left(\mathrm{a}^{\prime}\right)$, (b) and (c) are equivalent. Also (c) and $\left(\mathrm{c}^{\prime}\right)$ are equivalent by [9] 10.9. As in the previous case we deduce that d) implies (b) and (e) implies (d). The proof of Lemma 1 is complete.

If $\pi$ is any infinite set of primes then the direct product $\mathrm{D}(\pi)$ of cyclic groups of order $\mathrm{q}$ one for each $\mathrm{q}$ in $\pi$ satisfies (c) but not (d). The additive group $\mathrm{Q}$ of the field $\mathbf{Q}$ of rational numbers satisfies (d) but not (e). Also $\mathrm{D}(\pi)$ embeds into $\operatorname{GL}(1, \mathbf{C})$. If $\mathrm{p} \notin \pi$ then $\mathrm{D}(\pi)$ embeds into $\mathrm{GL}(1, \mathrm{~F})$ where $\mathrm{F}$ is the algebraic closure of the field of $\mathrm{p}$ elements. Further Q embeds into GL(1, C) (even into GL(2, Q)) and if $\mathrm{p}>0$ also into GL(1, F) for $\mathrm{F}$ any large enough field of characteristic p (see [9] 2.2).

Lemma 2 Let $\mathrm{G}$ be an $\mathbf{X}$-Engel subgroup of $\mathrm{GL}(\mathrm{n}, \mathrm{F})$, where the class $\mathbf{X}$ satisfies $\mathbf{S X}=\mathbf{X}$ (i.e. $\mathbf{X}$ is subgroup closed) and does not contain the free group of rank 2 . If $\mathrm{charF}=0$, then $\mathrm{G}$ is soluble-by-finite. If $\mathrm{charF}=\mathrm{p}>0$, then $\mathrm{G}$ is soluble-by-(locally finite and linear of characteristic $\mathrm{p})$.

Proof Suppose $\mathrm{H}=<\mathrm{x}, \mathrm{y}>\leq \mathrm{G}$ is free of $\operatorname{rank} 2$ on $\{\mathrm{x}, \mathrm{y}\}$. Then $\mathrm{H}$ is $\mathbf{X}$-Engel, so a sink for $\mathrm{y}$ in $\mathrm{H}$ is either trivial or infinite cyclic. But

$$
[\mathrm{x}, \mathrm{m} y]^{\mathrm{h}}=\mathrm{y}^{-(\mathrm{m}-1)} \mathrm{x}^{-1} \ldots \mathrm{xy}^{\mathrm{m}} \text { for all } \mathrm{m} \geq 1 \text { and } \mathrm{h} \geq 1 .
$$

Thus $\left[\mathrm{x},{ }_{\mathrm{m}}^{\mathrm{y}}\right]^{\mathrm{h}} \neq\left[\mathrm{x},{ }_{\mathrm{m}+2} \mathrm{y}\right]^{\mathrm{k}}$ for all $\mathrm{m} \geq 1, \mathrm{~h} \geq 1$ and $\mathrm{k} \in \mathbf{Z}$. Consequently $<\left[\mathrm{x},{ }_{\mathrm{m}} \mathrm{y}\right],[\mathrm{x}$, $\left.{ }_{m+2} y\right]>$ is not cyclic and hence neither is $<\left[x,{ }_{n} y\right]: n \geq m>$ for any $m \geq 1$. Therefore no such $\mathrm{H}$ exists and the claims of Lemma 2 follow from [9] 10.17 (Tits' theorem), 5.11 and 6.4.

Lemma 3 Let $\mathrm{A}$ be a module over a group $\mathrm{G}$ with $\mathrm{A}$ additively a q-group for some prime q. For each $\mathrm{i} \geq 1$ set $\mathrm{A}_{\mathrm{i}}=\left\{\mathrm{a} \in \mathrm{A}: \mathrm{q}^{\mathrm{i}} \mathrm{a}=0\right\}$. If $\mathrm{A}_{1}$ is $\mathrm{G}-$ hypercentral, then so is $\mathrm{A}$.

Proof Clearly each $A_{i}$ is a G-submodule of $A, A_{i} \leq A_{i+1}$ for each $i$ and $A=\bigcup_{i} A_{i}$. Also multiplication by $q^{i}$ determines a G-embedding of $A_{i+1} / A_{i}$ into $A_{1}$. Thus each $A_{i+1} / A_{i}$ is G-hypercentral and consequently so is A.

Lemma 4 Let $\mathrm{G}$ be a subgroup of $\mathrm{GL}(\mathrm{n}, \mathrm{F})$, where $\mathrm{F}$ is an algebraically closed field of positive characteristic. Suppose $\mathrm{A}$ is an abelian normal subgroup of $\mathrm{G}$ of finite rank. Then there exists a normal subgroup $\mathrm{D} \leq \mathrm{A}$ of $\mathrm{G}$ with $\mathrm{A} / \mathrm{D}$ finite and the index $\left(\mathrm{G}: \mathrm{C}_{\mathrm{G}}(\mathrm{D})\right)$ dividing $\mathrm{n}$ !.

Proof Let $\mathrm{a}=\mathrm{a}_{\mathrm{u}} \mathrm{a}_{\mathrm{d}}$ denote the Jordan decomposition of the element a of A (see [9] 7.2) and set $A_{u}=\left\{a_{u}: a \in A\right\}$ and $A_{d}=\left\{a_{d}: a \in A\right\}$. The (Zariski) closure of $A$ in GL(n, F) is abelian ([9] 5.11) and contains $A_{u}$ and $A_{d}$ ([9] 7.3). Then $A_{u}$ and $A_{d}$ are subgroups of GL(n, F) (see [9] 7.1) that are normalized by $G$. Also $A A_{d}=A_{u} A=A_{u} \times A_{d}$.

Now $A_{u}$ is unipotent and $A_{d}$ is diagonalizable ([9] 7.1). Further $A_{u} \cong A A_{d} / A_{d}$ has finite rank, as well as being abelian of finite exponent. Therefore $A_{u}$ is finite and consequently so is $A /\left(A \cap A_{d}\right) \cong A_{u}$. Set $D=A \cap A_{d}$. Finally $\left(G: C_{G}(D)\right)$ divides $n$ ! by [9] 1.12.

For any group $\mathrm{G}$ denote its upper central series by $\left\{\zeta_{\mathrm{s}}(\mathrm{G}): 0 \leq \mathrm{s} \leq \sigma\right\}$, s and $\sigma$ ordinals and its hypercentre by $\zeta(\mathrm{G})=\bigcup_{\mathrm{s}} \zeta_{\mathrm{s}}(\mathrm{G})$. Recall, $\mathbf{F}$ denotes the class of finite groups. 
Lemma 5 Let $\mathbf{X}$ be a class of groups and $\mathrm{A} \leq \mathrm{T}$ normal subgroups of a group $\mathrm{G}$ with [A, $\mathrm{T}]=<1>$ and $\mathrm{G} / \mathrm{T}$ finite such that for each $\mathrm{g}$ in $\mathrm{G}$ there is a sink $\mathrm{A}(\mathrm{g}) \in \mathbf{X}$ in $\mathrm{A}$. If

(a) $\mathbf{X}=\mathrm{SX}$ and whenever $\mathrm{U}, \mathrm{V} \leq \mathrm{W}$, where $\mathrm{W}$ is an abelian group and $\mathrm{U}$ and $\mathrm{V}$ lie in $\mathbf{X}$, then $\mathrm{UV} \in \mathbf{X}$, or

(b) $\mathbf{X}=\mathrm{SX}=\mathrm{QX}=\mathrm{D}_{0} \mathbf{X}$ ( $\mathrm{Q}$ the quotient operator and $\mathrm{D}_{0}$ the (direct product of finitely many groups) operator), or

(c) $\mathbf{X}=\mathbf{X}_{\mathrm{ftr}}$,

then there exists a normal $\mathbf{X}$-subgroup $\mathrm{B} \leq \mathrm{A}$ of $\mathrm{G}$ with $\mathrm{A} / \mathrm{B} \leq \zeta_{\omega}(\mathrm{G} / \mathrm{B})$. If also $\mathrm{A}=\mathrm{T}$, then $\mathrm{G}$ is $\mathbf{X F}$-by-hypercentral.

Note that $\mathbf{X}_{\mathrm{fr}}$ and $\mathbf{X}_{\mathrm{mm}}$ both satisfy (b) but $\mathbf{X}_{\mathrm{ftr}}$ does not. Also $\mathbf{X F}=\mathbf{X}$ for $\mathbf{X}=\mathbf{X}_{\mathrm{fr}}, \mathbf{X}_{\mathrm{ftr}}$ or $\mathbf{X}_{\mathrm{mm}}$.

Proof (a) Let $\mathrm{X}$ be a (finite) transversal of $\mathrm{T}$ to $\mathrm{G}$. Now for each $\mathrm{g}$ in $\mathrm{G}$, a in A and large enough $n$ we have $[\mathrm{a}, \mathrm{ng}] \in \mathrm{A}(\mathrm{g})$. Clearly $\mathrm{g}=$ by for some $\mathrm{b}$ in $\mathrm{T}$ and $\mathrm{y}$ in $\mathrm{X}$ and then $A(x)^{y}=A(x)^{g}$. Set

$$
\mathrm{B}=<\mathrm{A}(\mathrm{x})^{\mathrm{g}}: \mathrm{x} \in \mathrm{X}, \mathrm{g} \in \mathrm{G}>=<\mathrm{A}(\mathrm{x})^{\mathrm{y}}: \mathrm{x}, \mathrm{y} \in \mathrm{X}>.
$$

Clearly $\mathrm{B} \leq \mathrm{A}$ is normal in $\mathrm{G}$ and $\mathrm{B} \in \mathbf{X}$. Also $\mathrm{A} / \mathrm{B}$ consists of right Engel elements of $\mathrm{G} / \mathrm{B}$. Consequently $\mathrm{A} / \mathrm{B} \leq \zeta_{\omega}(\mathrm{G} / \mathrm{B})$ by [9] 8.1 .

Suppose $A=T$. Then $(\mathrm{G} / \mathrm{B}: \zeta(\mathrm{G} / \mathrm{B})$ ) is finite, so by [3] (or see Theorem $\mathrm{C}$ of [13]) there exists N/B, a finite normal subgroup of $\mathrm{G} / \mathrm{B}$, such that $\mathrm{G} / \mathrm{N}$ is hypercentral. Trivially $\mathrm{N} \in \mathbf{X F}$.

(b) $\mathrm{UV} \cong(\mathrm{U} \times \mathrm{V}) /\{(\mathrm{u}, \mathrm{v}): \mathrm{u} \in \mathrm{U}, \mathrm{v} \in \mathrm{V}, \mathrm{uv}=1\} \in \mathrm{QD}_{0} \mathbf{X}=\mathbf{X}$. Now apply a).

(c) By (b) there exists $\mathrm{B} \leq \mathrm{A}$ with $\mathrm{B}$ normal in $\mathrm{G}, \mathrm{A} / \mathrm{B}$ G-hypercentral and rankB finite. Let $\mathrm{P}=\tau(\mathrm{B})$. Now for any $\mathrm{g}$ in $\mathrm{G}, \mathrm{A}(\mathrm{g}) \cap \mathrm{P} \in \mathrm{SX}=\mathbf{X}$, so $\mathrm{A}(\mathrm{g}) \cap \mathrm{P}$ is Chernikov and hence so is $S_{0}=<A(x) \cap P: x \in X>$. There is a finite set $\pi$ of primes such that $S_{0} \leq S=O_{\pi}(P)$. Choose $\pi$ to contain all the prime divisors of $(G: T)$. Note that $S$ is also Chernikov. Further $\mathrm{P} / \mathrm{S}$ consists of right Engel elements of $\mathrm{G} / \mathrm{S}$ and $\mathrm{C}_{\mathrm{G}}(\mathrm{P}) \geq \mathrm{T}$ has finite index in $\mathrm{G}$. Therefore $\mathrm{P} / \mathrm{S}$ is G-hypercentral by [9] 8.1 again.

Pick $U \leq B$ maximal subject to $P \cap U=S$. Then $B / U$ is a (periodic) $\pi^{\prime}$-group and hence so is $B / U_{G}$ for $U_{G}=\bigcap_{g \in G} U^{g}=\bigcap_{x \in X} U^{x}$. Clearly $P \cap U_{G}=S$. Now choose $V \leq B$ maximal subject to $\mathrm{U}_{\mathrm{G}} \leq \mathrm{V} \leq \mathrm{B}, \mathrm{V}$ normal in $\mathrm{G}$ and $\mathrm{P} \cap \mathrm{V}=\mathrm{S}$. Clearly $\mathrm{B} / \mathrm{V}$ is a $\pi^{\prime}$-group. Let $\mathrm{q} \in \pi^{\prime}$ and set $\mathrm{B}_{\mathrm{q}}=\left\{\mathrm{b} \in \mathrm{B}: \mathrm{b}^{\mathrm{q}} \in \mathrm{V}\right\}$. Then $\mathrm{B}_{\mathrm{q}} / \mathrm{V}$ is a finite (recall rankB is finite) $\mathbf{F}_{\mathrm{q}} \mathrm{G}$-module. Moreover $T \leq C_{G}(B)$ and $G / T$ is a finite $\pi$-group. Therefore $B_{q} / V$ is completely reducible as $\mathbf{F}_{\mathrm{q}} \mathrm{G}$-module (Maschke's theorem). If I/V is an irreducible $\mathbf{F}_{\mathrm{q}} \mathrm{G}$-submodule of $\mathrm{B}_{\mathrm{q}} / \mathrm{V}$, then $\mathrm{P} \cap \mathrm{I}>\mathrm{S}=\mathrm{P} \cap \mathrm{V}$, so $(\mathrm{P} \cap \mathrm{I}) \mathrm{V}=\mathrm{I}$. Hence $\mathrm{B}_{\mathrm{q}} \leq \mathrm{PV}$. Also $\mathrm{PV} / \mathrm{V} \cong \mathrm{P} / \mathrm{S}$ is G-hypercentral. Consequently $\mathrm{B} / \mathrm{V}$ is G-hypercentral by Lemma 3. We chose B with A/B G-hypercentral. Hence $A / V$ is G-hypercentral. Also $P \cap V=S$, which is Chernikov and $V /(P \cap V) \cong V P / P \leq B / P$, which is torsion-free abelian of finite rank. Therefore $\mathrm{V} \in \mathbf{X}_{\mathrm{ftr}}$

Finally suppose $A=T$. Then $(G / V: \zeta(G / V)$ ) is finite. Hence there exists ([3] again) N/V, a finite normal subgroup of $\mathrm{G} / \mathrm{V}$ with $\mathrm{G} / \mathrm{N}$ hypercentral. Clearly $\mathrm{N} \in \mathbf{X}_{\mathrm{ftr}}$. The proof of Lemma 5 is complete.

Lemma 6 Let $\mathrm{G}$ be a group with $\mathrm{G} / \zeta(\mathrm{G})$ locally finite. Then there exists a locally finite normal subgroup $\mathrm{K}$ of $\mathrm{G}$ with $\mathrm{G} / \mathrm{K}$ hypercentral. 
Proof Let $\mathrm{X}$ be a finitely generated subgroup of $\mathrm{G}$. Then $\mathrm{X} / \zeta(\mathrm{X})$ is finite, so there exists $\mathrm{N}_{X}$ a finite normal subgroup of $X$ with $X / N_{X}$ hypercentral ([3] again). Choose $N_{X}$ of least order. If $Y$ is a finitely generated subgroup of $G$ containing $X$, then $X \cap N_{Y} \geq N_{X}$. Set $\mathrm{N}=\bigcup_{X} \mathrm{~N}_{X}$. Then $\mathrm{N}$ is a locally finite normal subgroup of $\mathrm{G}$ with $\mathrm{G} / \mathrm{N}$ locally nilpotent.

Define $K$ by $K / N=\tau(G / N)$. Then $K$ is also locally finite and $H=G / K$ is locally nilpotent and torsion-free with $\mathrm{H} / \zeta(\mathrm{H})$ locally finite. Now $\zeta_{1}(\mathrm{H})$ is isolated in $\mathrm{H}$, see [5] 2.3.8, so $\mathrm{H} /$ $\zeta_{1}(\mathrm{H})$ is torsion-free. A simple induction yields that $\mathrm{H} / \zeta(\mathrm{H})$ is also torsion-free. But $\mathrm{H} / \zeta(\mathrm{H})$ is locally finite. Therefore $\mathrm{H}=\zeta(\mathrm{H})$; that is, $\mathrm{G} / \mathrm{K}$ is hypercentral.

\section{Positive characteristic case}

The proposition below completes the proof of Theorem 1 .

Proposition 1 Let $\mathrm{G}$ be an $\mathbf{X}$-Engel subgroup of $\mathrm{GL}(\mathrm{n}, \mathrm{F})$, where $\mathrm{n}$ is a positive integer and $\mathrm{F}$ is a field of positive characteristic $\mathrm{p}$. Suppose one of the following holds.

(i) $\mathbf{X}$ is a class of groups of finite rank satisfying $\mathbf{X}=\mathbf{S X}=\mathbf{Q X}=\mathrm{D}_{0} \mathbf{X}=\mathbf{X F}$.

(ii) $\mathbf{X}=\mathbf{X}_{\mathrm{ftr}}$

(iii) $\mathbf{X}=\mathbf{X}_{\mathrm{fh}}$.

(iv) $\mathbf{X}=\mathrm{LF}$.

Then $\mathrm{G}$ is $\mathbf{X}$-by-hypercentral.

Proof (i) We make heavy use in this case of $\mathbf{X}=\mathrm{QX}$, which is why we have to handle (ii) separately. We mirror the proof of Theorem $\mathrm{S}$ in [14].

(a) $\mathrm{G}$ is soluble-by-finite.

If this is false, then using Lemma 2 we may assume that $\mathrm{G}$ is infinite, periodic and simple, and then that $\mathrm{G}$ is of Lie type. Then, using [1] 6.3.1, we may assume that $\mathrm{G}$ is actually $\operatorname{PSL}(2, \mathrm{k})$ for some locally finite, infinite field $\mathrm{k}$ of characteristic $\mathrm{p}$. Consider $\operatorname{SL}(2$, $\mathrm{k}) \cap \operatorname{Tr}(2, \mathrm{k})$, which is isomorphic to the split extension $\mathrm{H}=\mathrm{k}^{*} \mathrm{k}^{+}$, where $\mathrm{k}^{+}$denotes the additive and $\mathrm{k}^{*}$ the multiplicative group of $\mathrm{k}$ and $\mathrm{k}^{*}$ acts on $\mathrm{k}^{+}$via squares (i.e. $\mathrm{b}^{\mathrm{a}}=\mathrm{ba}^{2}$ for $\mathrm{a} \in \mathrm{k}^{*}$ and $\left.\mathrm{b} \in \mathrm{k}^{+}\right)$.

We show that $\mathrm{H}$ modulo $<-1>\leq \mathrm{k} *$ is not $\mathbf{X}$-Engel, which will show that $\operatorname{PSL}(2, \mathrm{k})$ is not $\mathbf{X}$-Engel either and will complete the proof of (a). For if otherwise, then $h \in H$ would have a sink $\mathrm{E} \in \mathbf{X}$ in $\mathrm{H}$ with $\mathrm{E} \leq \mathrm{k}^{+}$. But $\mathrm{E}$ has finite rank and $\mathrm{k}^{+}$is elementary abelian. Thus $\mathrm{E}$ is finite, $\mathrm{H}$ is finite-Engel and $\mathrm{H}$ is finite-by-hypercentral (Shumyatsky's theorem, [8] or [14]). Then $(\mathrm{H}: \zeta(\mathrm{H}))$ is finite by the theorem of [2]. But if $\mathrm{a} \in \mathrm{k}^{*} \mid<-1>$ and $\mathrm{b} \in \mathrm{k}^{+} \mid<0>$, then $\mathrm{b}^{\mathrm{a}}=\mathrm{ba}^{2} \neq \mathrm{b}$. Hence $\mathrm{k}^{+} \cap \zeta_{1}(\mathrm{H})=\left\langle 0>, \mathrm{k}^{+} \cap \zeta(\mathrm{H})=<0>\right.$ and $\mathrm{k}$ is finite, which is false. Claim a) is now proved.

(b) If $\mathrm{G} \leq \operatorname{Tr}(\mathrm{n}, \mathrm{F})$, then $\mathrm{G}$ is finite-by-nilpotent.

For if $\mathrm{E}$ is an $\mathbf{X}$-subgroup of $\mathrm{G}^{\prime} \leq \operatorname{Tr}_{1}(\mathrm{n}, \mathrm{F})$, then $\mathrm{E}$ has finite rank as well as being nilpotent of finite exponent. Consequently $\mathrm{E}$ is finite, $\mathrm{G}$ is finite-Engel and (b) of the proof of Theorem $S$ of [14] applies directly.

(c) $\mathrm{G}$ is nilpotent-by-finite.

(c) Follows almost immediately from (b). In fact, cf. the proof of (c) in [14] Theorem 1.1, the connected component $\mathrm{G}^{\mathrm{o}}$ of $\mathrm{G}$ containing 1 is nilpotent. 
(d) $\mathrm{G}$ is $\mathbf{X}$-by-hypercentral.

Let $\mathrm{N}$ be a nilpotent normal subgroup of $\mathrm{G}$ of finite index. We may reduce to the two cases where $\mathrm{N}$ is unipotent or $\mathrm{N}$ is a d-group, see Remark 3.3 of [14].

If $\mathrm{N}$ is unipotent, since $\mathbf{X}$-groups have finite rank, every $\mathbf{X}$-subgroup of $\mathrm{G}$ is finite. Consequently $\mathrm{G}$ is finite-Engel, finite-by-hypercentral and therefore $\mathbf{X}$-by hypercentral (recall $\mathbf{F} \subseteq \mathbf{X}$ ). Suppose $\mathrm{N}$ is a d-group. Then $\mathrm{N}$ is abelian-by-finite by [9] 7.7 and 3.5 and consequently so is $\mathrm{G}$. Here $\mathbf{X F}=\mathbf{X}$. Therefore $\mathrm{G}$ is $\mathbf{X}$-by-hypercentral by Lemma 5. The proof of Part (i) is now complete.

(ii) Here $\mathbf{X}$ is $\mathbf{X}_{\mathrm{ftr}}$. By Part (i) there is a normal subgroup $\mathrm{X}$ of $\mathrm{G}$ of finite rank with $\mathrm{G} / \mathrm{X}$ hypercentral. Using Lemma 1 it follows that $\mathrm{X}^{\mathrm{o}}$ is abelian, normal in $\mathrm{G}$ and of finite index in $X$. By Lemma 4 there exists a normal subgroup $Y \leq X^{0}$ of $G$ with $(X: Y)$ finite and $\left(\mathrm{G}: \mathrm{C}_{\mathrm{G}}(\mathrm{Y})\right)$ dividing $\mathrm{n}$ !. By Lemma 5 there is a normal $\mathbf{X}_{\mathrm{ftr}}$-subgroup $\mathrm{Z} \leq \mathrm{Y}$ of $\mathrm{G}$ with $\mathrm{Y} / \mathrm{Z} \leq \zeta(\mathrm{G} / \mathrm{Z})$. Now $\mathrm{X} / \mathrm{Y}$ is finite and $\mathrm{G} / \mathrm{X}$ is hypercentral. Hence $(\mathrm{G} / \mathrm{Y}: \zeta(\mathrm{G} / \mathrm{Y}))$ is finite by the theorem of [2]. But then $(\mathrm{G} / \mathrm{Z}: \zeta(\mathrm{G} / \mathrm{Z}))$ is also finite, so by [3] there exists $N / Z$ a finite normal subgroup of G/Z with $\mathrm{G} / \mathrm{N}$ hypercentral. Finally $\mathrm{Z}$ and hence $\mathrm{N}$ lie in $\mathbf{X}_{\mathrm{ftr}}$.

(iii) Here $\mathbf{X}$ is $\mathbf{X}_{\mathrm{fh}}$. By Lemma 2 there is a soluble normal subgroup $\mathrm{N}$ of $\mathrm{G}$ with $\mathrm{G} / \mathrm{N}$ locally finite. We may choose $\mathrm{N}$ triangularizable (over an extension of $\mathrm{F}$ ) and closed in $\mathrm{G}$. Then $\mathrm{O}_{\mathrm{p}}(\mathrm{N})$ is also closed in $\mathrm{G}$ and hence $\mathrm{H}=\mathrm{G} / \mathrm{O}_{\mathrm{p}}(\mathrm{N})$ is isomorphic to a linear group of characteristic p, see [9] 6.4, such that the image $\mathrm{M}$ of $\mathrm{N}$ is abelian and contains no nontrivial unipotent (i.e. p-) elements. Hence there is a linear representation of $\mathrm{H}$ faithful on $\mathrm{M}$ and such that the image of $\mathrm{M}$ is diagonalizable (see Remark 3.3 of [14]). Then 1.12 of [9] yields that $\left(\mathrm{G}: \mathrm{C}_{\mathrm{G}}\left(\mathrm{N} / \mathrm{O}_{\mathrm{p}}(\mathrm{N})\right)=\left(\mathrm{H}: \mathrm{C}_{\mathrm{H}}(\mathrm{M})\right)\right.$ is finite. Set $\mathrm{T}=\tau(\mathrm{N}) \geq \mathrm{O}_{\mathrm{p}}(\mathrm{N})$. Then N/T is torsion-free abelian, so any $\mathbf{X}_{\mathrm{fh}}$-subgroup of N/T lies in $\mathbf{X}_{\mathrm{fr}}$ By Lemma 5 there exists $\mathrm{S}$ a normal subgroup of $\mathrm{G}$ with $\mathrm{T} \leq \mathrm{S} \leq \mathrm{N}$, with $\mathrm{S} / \mathrm{T} \in \mathbf{X}_{\text {fr }}$ and with $\mathrm{N} / \mathrm{S} \leq \zeta(\mathrm{G} / \mathrm{S})$. By Lemma 6 applied to $\mathrm{G} / \mathrm{S}$ there is a normal subgroup $\mathrm{K}$ of $\mathrm{G}$ with $\mathrm{S} \leq \mathrm{K}$, with $\mathrm{K} / \mathrm{S}$ locally finite and $\mathrm{G} / \mathrm{K}$ hypercentral. Clearly $\mathrm{K} \in \mathbf{X}_{\mathrm{fh}}$. This completes the proof of (iii).

(iv) Here $\mathbf{X}$ is LF. Set $T=\tau(G) \geq \mathrm{O}_{p}(G)$. Now $\mathrm{O}_{\mathrm{p}}(\mathrm{G})$ is closed in $\mathrm{G}$, so $\mathrm{G} / \mathrm{O}_{\mathrm{p}}(\mathrm{G})$ is isomorphic to some linear group of characteristic $p$ ([9] 6.4). Therefore $\mathrm{G} / \mathrm{T}$ is also isomorphic to a linear group of characteristic $\mathrm{p}$, see [10]. Consequently we may assume that $\mathrm{T}=\langle 1\rangle$. Certainly $\mathrm{G}$ is $\mathbf{X}_{\mathrm{fh}}$-Engel so by iii) there is a normal subgroup $\mathrm{N}$ of $\mathrm{G}$ with $\mathrm{G} / \mathrm{N}$ hypercentral and $N \in \mathbf{X}_{\text {fh. }}$. Also $\tau(N) \leq T=<1>$, so $N$ is soluble-by-finite with $\mathrm{O}_{\mathrm{p}}(\mathrm{N})=<1>$. Hence $\mathrm{N}$ contains a normal subgroup $\mathrm{M}$ of $\mathrm{G}$ with $\mathrm{N} / \mathrm{M}$ finite and $\mathrm{M}$ torsion-free abelian.

Now $\mathrm{G}$ is LF-Engel. If $\mathrm{g} \in \mathrm{G}$ there exists a locally finite subgroup of $\mathrm{M}$ that is a $\mathrm{g}$-sink in $\mathrm{M}$ and yet $\mathrm{M}$ is torsion-free. Hence $\mathrm{M}$ consists of right Engel elements of $\mathrm{G}$ and consequently $\mathrm{M} \leq \zeta(\mathrm{G})$ by [9] 8.1. Finally $\mathrm{G} / \mathrm{M}$ is finite-by-hypercentral, so $(\mathrm{G} / \mathrm{M}: \zeta(\mathrm{G} / \mathrm{M}))$ is finite by [2]. But then $(\mathrm{G}: \zeta(\mathrm{G}))$ is finite, so there exists a finite normal subgroup $\mathrm{K}$ of $\mathrm{G}$ with $\mathrm{G} / \mathrm{K}$ hypercentral by [3]. Consequently $\mathrm{G}$ is LF-by-hypercentral. (Actually here $\mathrm{K}=<1>$ since $\mathrm{T}=<1>$ and $\mathrm{G}$ itself is hypercentral.) The proof of Proposition 1 is now complete.

\section{Characteristic zero case}

Lemma 7 Let $\mathrm{F}$ be a field of characteristic 0, A a non-trivial subgroup of the multiplicative group $\mathrm{F}^{*}$ of $\mathrm{F}$ and $\mathrm{B}$ a non-zero subgroup of the additive group $\mathrm{F}^{+}$of $\mathrm{F}$ such that $\mathrm{BA}=\mathrm{B}$. Suppose the split extension $\mathrm{G}$ of $\mathrm{B}$ by $\mathrm{A}$ is $\mathbf{X}_{\mathrm{fr}}$-Engel. Then $\mathrm{B}$ has finite rank. If $\mathrm{G}$ is actually $\mathbf{X}_{\mathrm{mm}}$-Engel then $\mathrm{A}$ is finitely generated and $\mathrm{B}$ is minimax. 
Note that $B$ is torsion-free abelian, so total-rankB $=$ rankB. In particular the $\mathrm{G}$ in Lemma 7 is $\mathbf{X}_{\mathrm{fr}}$-Engel if and only if $\mathrm{G}$ is $\mathbf{X}_{\mathrm{ftr}}$-Engel.

Proof Choose $\mathrm{a} \in \mathrm{A} \mid<1>$. By hypothesis there is a subgroup $\mathrm{E}$ of $\mathrm{B}$ of finite rank such that for all $b$ in $B$ there exists an integer $m(b) \geq 1$ such that for all $n \geq m(b)$ we have $b(a-1)^{n} \in E$. Subject to this we choose our $E$ of least possible rank. Set $E_{1}=<b(a-1)^{n}$ : $\mathrm{n} \geq \mathrm{m}(\mathrm{b}), \mathrm{b} \in \mathrm{B}>\leq \mathrm{E}$. Then $\mathrm{E}_{1}$ is also of finite rank (even minimax if $\mathrm{E}$ is minimax), so we may assume that $\mathrm{E}=\mathrm{E}_{1}$. Clearly now $\mathrm{E}(\mathrm{a}-1) \leq \mathrm{E}$.

Since $a \neq 1$, so $a-1 \in F^{*}$ is an (additive) automorphism of $F^{+}$. Thus $E(a-1) \cong E$ and

$$
\cdots \geq \mathrm{E}(\mathrm{a}-1)^{-\mathrm{i}} \geq \cdots \geq \mathrm{E}(\mathrm{a}-1)^{-1} \geq \mathrm{E} \geq \mathrm{E}(\mathrm{a}-1) \geq \cdots \geq \mathrm{E}(\mathrm{a}-1)^{\mathrm{i}} \geq \cdots
$$

where $i$ runs over the positive integers. Set $E_{2}=\bigcup_{i \geq 0} E(a-1)^{-i}$. If $b \in B$, then for some $\mathrm{n} \geq 1$ we have $\mathrm{b}(\mathrm{a}-1)^{\mathrm{n}} \in \mathrm{E}$, so $\mathrm{b} \in \mathrm{E}(\mathrm{a}-1)^{-\mathrm{n}}$. Therefore $\mathrm{B} \leq \mathrm{E}_{2}$. Clearly $\mathrm{E}_{2}$ and $\mathrm{B}$ have finite rank, in fact rank equal to the rank of $\mathrm{E}$.

(Further $\mathrm{E}(\mathrm{a}-1) \leq \mathrm{E}$ yields that $\mathrm{Ea} \leq \mathrm{E}$. Also $\mathrm{BA}=\mathrm{B}$, so $\mathrm{E}_{3}=\mathrm{E}<\mathrm{a}>=\bigcup_{\mathrm{i} \geq 0} \mathrm{Ea}^{-\mathrm{i}} \leq \mathrm{B}$. Suppose $b \in B$ with $b a \in E$. There exists $n \geq 1$ with $b(a-1)^{n} \in E$. Then $(-1)^{n} b \in E$. For any $\mathrm{b} \in \mathrm{E}_{3}$ we have $\mathrm{ba}^{\mathrm{m}} \in \mathrm{E}$ for some $\mathrm{m} \geq 1$, so $\left(\mathrm{ba}^{\mathrm{m}-1}\right) \mathrm{a} \in \mathrm{E}$ and thus $\mathrm{ba}^{\mathrm{m}-1} \in \mathrm{E}$. A trivial induction yields that $\mathrm{b} \in \mathrm{E}$. This shows that $\mathrm{E}_{3}=\mathrm{E}$ and hence $\mathrm{E}$ is normalized by $<\mathrm{a}>$. It follows that every a-sink in $<\mathrm{a}>\mathrm{B}$ contains a normal such a-sink.)

Since we chose $\mathrm{E}$ of least rank, so $\mathrm{E} / \mathrm{E}(\mathrm{a}-1)$ periodic. But

$$
\mathrm{E}(\mathrm{a}-1)^{-\mathrm{i}} / \mathrm{E}(\mathrm{a}-1)^{-\mathrm{i}+1}
$$

is isomorphic to $E / E(a-1)$ for each $i$. Therefore $E_{2} / E$ is a periodic. Now assume $E$ is mini$\max$. Then $\mathrm{E} / \mathrm{E}(\mathrm{a}-1)$ is a Chernikov $\pi$-group for some finite set $\pi$ of primes. It follows that $\mathrm{B} / \mathrm{E}$ is a $\pi$-group of finite rank and therefore $\mathrm{B} / \mathrm{E}$ is Chernikov. Consequently $\mathrm{B}$ is minimax.

Finally it remains to prove in the minimax case that $\mathrm{A}$ is finitely generated. Let $\mathrm{J}$ be the subring of $\mathrm{F}$ generated by $\mathrm{A}$. Then $\mathrm{J}$ is a domain and $\mathrm{B}$ is a faithful $\mathrm{J}$-module. Also $\mathrm{B}$ is torsion-free and, by the above, minimax. Hence $\mathrm{B}$ has a free abelian subgroup $\mathrm{B}_{0}$ of rank $\mathrm{r}=\operatorname{rankB}$ with $\mathrm{B} / \mathrm{B}_{0}$ a periodic $\pi$-group for some finite set $\pi$ of primes. Let $t$ denote the product of all the elements of $\pi$. Then the tensor product $\mathbf{Z}\left[\mathrm{t}^{-1}\right] \mathrm{B}$ of $\mathbf{Z}\left[\mathrm{t}^{-1}\right]$ by $\mathrm{B}$ over $\mathbf{Z}$ is equal to $\mathbf{Z}\left[\mathrm{t}^{-1}\right] \mathrm{B}_{0}$ and hence is isomorphic to $\mathbf{Z}\left[\mathrm{t}^{-1}\right]^{(\mathrm{r})}$, the free $\mathbf{Z}\left[\mathrm{t}^{-1}\right]$-module of rank $\mathrm{r}$. Therefore $\mathbf{J}$ embeds into the endomorphism ring of this module and hence into the matrix ring $\mathbf{Z}\left[\mathrm{t}^{-1}\right]^{\mathrm{r}^{\prime}}$, where $\mathrm{r}^{\prime}$ denotes $\mathrm{r} \times \mathrm{r}$.

There exists a finitely generated subring $R \geq \mathbf{Z}\left[\mathrm{t}^{-1}\right]$ of the complex numbers, an element $x$ of $G L(r, R)$ and a subgroup $A_{0}$ of $A$ of finite index such that $\left(A_{0}\right)^{x} \leq \operatorname{Tr}(r, R)$. (We now regard $J \supseteq A$ as a subring of $R^{r^{\prime}}$ via the obvious embeddings $J \leq Z\left[t^{-1}\right]^{r^{\prime}} \leq R^{r^{\prime}}$.) If a $\in A_{0}$ with $\mathrm{a}^{\mathrm{x}}$ unipotent, then $\left(\mathrm{a}^{\mathrm{x}}-1\right)^{\mathrm{r}}=0$ in $\mathrm{R}^{\mathrm{r}^{\prime}}$ and hence $(\mathrm{a}-1)^{\mathrm{r}}=0$ in the domain J. Consequently $\mathrm{a}=1$ and the unipotent radical of $\left(\mathrm{A}_{0}\right)^{\mathrm{x}}$ is trivial. It follows that $\mathrm{A}_{0}$ is isomorphic to a subgroup of the full diagonal group $\mathrm{D}(\mathrm{r}, \mathrm{R})$ and the latter is isomorphic to the direct product of $r$ copies of the group $U$ of units of $R$. But $R$ is a finitely generated domain so $U$ is finitely generated (e.g. [7]). Therefore $\mathrm{A}_{0}$ and $\mathrm{A}$ are also finitely generated. This completes the proof of Lemma 7.

Lemma 8 Let $\mathrm{X} \leq \mathrm{Y} \leq \mathrm{T}$ be subgroups of the group $\mathrm{G}$ with $\mathrm{X}$ normal in $\mathrm{T}$, $\mathrm{T}$ normal in $\mathrm{G}$ and $\mathrm{G} / \mathrm{T}$ finite. Set $\mathrm{X}_{\mathrm{G}}=\bigcap_{\mathrm{g} \in \mathrm{G}} \mathrm{X}^{\mathrm{g}}$ and similarly for $\mathrm{Y}_{\mathrm{G}}$. If $\mathrm{Y} / \mathrm{X}$ lies in some class $\mathrm{X}$ of groups, then $\mathrm{Y}_{\mathrm{G}} / \mathrm{X}_{\mathrm{G}}$ lies in $\mathrm{SD}_{0} \mathrm{X}$. If also $\mathrm{Y}$ is normal in $\mathrm{T}$ and if $\mathrm{Y}$ is any class of groups containing $\mathrm{T} / \mathrm{C}_{\mathrm{T}}(\mathrm{Y} / \mathrm{X})$, then $\mathrm{T} / \mathrm{C}_{\mathrm{T}}\left(\mathrm{Y}_{\mathrm{G}} / \mathrm{X}_{\mathrm{G}}\right) \in \mathrm{SD}_{0} \mathrm{QY}$. 
Our only application here of the second part of Lemma 8 is where $\mathbf{Y}$ is the class of finitely generated abelian groups.

Proof Clearly $\mathrm{X}_{\mathrm{G}} \leq \mathrm{X} \cap \mathrm{Y}_{\mathrm{G}}$, so $\mathrm{X}_{\mathrm{G}} \leq\left(\mathrm{X} \cap \mathrm{Y}_{\mathrm{G}}\right)_{\mathrm{G}} \leq \mathrm{X}_{\mathrm{G}}$ and $\mathrm{X}_{\mathrm{G}}=\left(\mathrm{X} \cap \mathrm{Y}_{\mathrm{G}}\right)_{\mathrm{G}}$. Now $\mathrm{Y} / \mathrm{X} \in \mathbf{X}$ implies $\mathrm{XY}_{\mathrm{G}} / \mathrm{X} \in \mathrm{SX}$. Hence $\mathrm{Y}_{\mathrm{G}} /\left(\mathrm{X}^{\mathrm{g}} \cap \mathrm{Y}_{\mathrm{G}}\right) \cong \mathrm{X}^{\mathrm{g}} \mathrm{Y}_{\mathrm{G}} / \mathrm{X}^{\mathrm{g}} \cong X \mathrm{XY}_{\mathrm{G}} / \mathrm{X} \in \mathrm{SX}$ for all $\mathrm{g}$ in $\mathrm{G}$. Therefore

$$
\mathrm{Y}_{\mathrm{G}} / \mathrm{X}_{\mathrm{G}}=\mathrm{Y}_{\mathrm{G}} /\left(\mathrm{X} \cap \mathrm{Y}_{\mathrm{G}}\right)_{\mathrm{G}}=\mathrm{Y}_{\mathrm{G}} / \cap_{\mathrm{g}}\left(\mathrm{X}^{\mathrm{g}} \cap \mathrm{Y}_{\mathrm{G}}\right) \in \mathrm{SD}_{0} \mathrm{SX}=\mathrm{SD}_{0} \mathbf{X},
$$

using that $\left(\mathrm{G}: \mathrm{N}_{\mathrm{G}}(\mathrm{X})\right) \leq(\mathrm{G}: \mathrm{T})$, which is finite.

Suppose $\mathrm{Y}$ is normal in $\mathrm{T}$. Since $\mathrm{C}_{\mathrm{T}}\left(\mathrm{XY}_{\mathrm{G}} / \mathrm{X}\right) \geq \mathrm{C}_{\mathrm{T}}(\mathrm{Y} / \mathrm{X})$ we have that

$$
\mathrm{T} / \mathrm{C}_{\mathrm{T}}\left(\mathrm{Y}_{\mathrm{G}} /\left(\mathrm{X}^{\mathrm{g}} \cap \mathrm{Y}_{\mathrm{G}}\right)\right) \cong \mathrm{T} / \mathrm{C}_{\mathrm{T}}\left(\mathrm{Y}_{\mathrm{G}} /\left(\mathrm{X} \cap \mathrm{Y}_{\mathrm{G}}\right)\right)=\mathrm{T} / \mathrm{C}_{\mathrm{T}}\left(\mathrm{XY}_{\mathrm{G}} / \mathrm{X}\right) \in \mathrm{QY} .
$$

Also $\mathrm{C}_{\mathrm{T}}\left(\mathrm{Y}_{\mathrm{G}} / \mathrm{X}_{\mathrm{G}}\right)=\bigcap_{\mathrm{g}} \mathrm{C}_{\mathrm{T}}\left(\mathrm{Y}_{\mathrm{G}} /\left(\mathrm{X}^{\mathrm{g}} \cap \mathrm{Y}_{\mathrm{G}}\right)\right)$, so $\mathrm{T} / \mathrm{C}_{\mathrm{T}}\left(\mathrm{Y}_{\mathrm{G}} / \mathrm{X}_{\mathrm{G}}\right) \in \mathrm{SD}_{0} \mathrm{QY}$.

Proposition 2 Let $\mathrm{G}$ be an $\mathbf{X}$-Engel subgroup of $\mathrm{GL}(\mathrm{n}, \mathrm{F})$, where $\mathrm{n}$ is a positive integer, $\mathrm{F}$ is a field of characteristic zero and $\mathbf{X}$ is $\mathbf{X}_{\mathrm{fr}}, \mathbf{X}_{\mathrm{ftr}}$ or $\mathbf{X}_{\mathrm{mm}}$. Then $\mathrm{G}$ has a normal series

$$
<1>=\mathrm{U}_{0} \leq \mathrm{V}_{1} \leq \mathrm{U}_{1} \leq \cdots \leq \mathrm{V}_{\mathrm{t}} \leq \mathrm{U}_{\mathrm{t}}=\mathrm{U} \leq \mathrm{T} \leq \mathrm{G}
$$

such that $\mathrm{t} \leq \mathrm{n}(\mathrm{n}-1) / 2, \mathrm{G} / \mathrm{T}$ is finite, $\mathrm{T} / \mathrm{U}$ is abelian, $\mathrm{U}$ is unipotent and for each $\mathrm{i}$ with $1 \leq \mathrm{i} \leq \mathrm{t},\left[\mathrm{U}_{\mathrm{i}}, \mathrm{U}\right] \leq \mathrm{U}_{\mathrm{i}-1}, \mathrm{U}_{\mathrm{i}} / \mathrm{U}_{\mathrm{i}-1}$ is torsion-free (abelian) and either $\mathrm{U}_{\mathrm{i}} / \mathrm{U}_{\mathrm{i}-1} \in \mathbf{X}$ with $\mathrm{V}_{\mathrm{i}}=\mathrm{U}_{\mathrm{i}}$, or, $\left[\mathrm{U}_{\mathrm{i}}, \mathrm{T}\right] \leq \mathrm{U}_{\mathrm{i}-1}$ with $\mathrm{V}_{\mathrm{i}} / \mathrm{U}_{\mathrm{i}-1} \in \mathbf{X}$ and $\mathrm{U}_{\mathrm{i}} / \mathrm{V}_{\mathrm{i}} \mathrm{G}$-hypercentral. Also there is a normal subgroup $\mathrm{S}$ of $\mathrm{G}$ with $\mathrm{U} \leq \mathrm{S}, \mathrm{S} / \mathrm{U} \in \mathbf{X}_{\mathrm{fr}}$ (even $\mathrm{S} / \mathrm{U} \in \mathbf{X}_{\mathrm{mm}}$ if $\mathbf{X}=\mathbf{X}_{\mathrm{mm}}$ ) and $\mathrm{G} / \mathrm{S}$ hypercentral. Further if $\mathbf{X}=\mathbf{X}_{\mathrm{mm}}$ then $\mathrm{T} / \mathrm{C}_{\mathrm{T}}\left(\mathrm{U}_{\mathrm{i}} / \mathrm{U}_{\mathrm{i}-1}\right)$ is finitely generated (and abelian) for all $\mathrm{i}$. Also $\mathrm{T}$ can be chosen to be triangularizable (over some extension field of $\mathrm{F}$ ) and any triangularizable normal subgroup of $\mathrm{G}$ of finite index (e.g. the connected component $\mathrm{G}^{\mathrm{o}}$ of $\mathrm{G}$ ) can be chosen to be $\mathrm{T}$.

Proof Now G is soluble-by-finite by Lemma 2, so there is a triangularizable (over some extension field of $\mathrm{F}$ ) normal subgroup $\mathrm{T}$ of $\mathrm{G}$ of finite index and we can choose $\mathrm{T}$ to be any one of these, e.g. $T=G^{o}$. Set $U=u(T)$, the unipotent radical of $T$, so $U$ is normal in $G$ and $\mathrm{T} / \mathrm{U}$ is abelian.

There is a normal series $<1>=\mathrm{U}_{0} \leq \mathrm{U}_{1} \leq \cdots \leq \mathrm{U}_{\mathrm{t}}=\mathrm{U}$ of $\mathrm{T}$ such that for each $\mathrm{i} \geq 1$ we have $\left[\mathrm{U}_{\mathrm{i}}, \mathrm{U}\right] \leq \mathrm{U}_{\mathrm{i}-1}$ with Lemma 7 applicable to each $\mathrm{U}_{\mathrm{i}} / \mathrm{U}_{\mathrm{i}-1}$ and $\mathrm{T} / \mathrm{C}_{\mathrm{T}}\left(\mathrm{U}_{\mathrm{i}} / \mathrm{U}_{\mathrm{i}-1}\right)$. Thus for each such i

$$
\begin{gathered}
\text { (*) }\left[\mathrm{U}_{\mathrm{i}}, \mathrm{U}\right] \leq \mathrm{U}_{\mathrm{i}-1}, \mathrm{U}_{\mathrm{i}} / \mathrm{U}_{\mathrm{i}-1} \text { is torsion-free abelian and } \\
\text { either } \mathrm{U}_{\mathrm{i}} / \mathrm{U}_{\mathrm{i}-1} \in \mathbf{X} \text { or }\left[\mathrm{U}_{\mathrm{i}}, \mathrm{T}\right] \leq \mathrm{U}_{\mathrm{i}-1} .
\end{gathered}
$$

Since $\mathrm{U}_{\mathrm{i}-1} \geq\left[\mathrm{U}_{\mathrm{i}}, \mathrm{U}\right]$, so $\mathrm{U}_{\mathrm{i}-1} \geq\left[\left(\mathrm{U}_{\mathrm{i}}\right)_{\mathrm{G}}, \mathrm{U}\right]$ and the latter is normal in G. Consequently $\left[\left(\mathrm{U}_{\mathrm{i}}\right)_{\mathrm{G}}, \mathrm{U}\right] \leq\left(\mathrm{U}_{\mathrm{i}-1}\right)_{\mathrm{G}}$. In the same way if $\left[\mathrm{U}_{\mathrm{i}}, \mathrm{T}\right] \leq \mathrm{U}_{\mathrm{i}-1}$ then $\left[\left(\mathrm{U}_{\mathrm{i}}\right)_{\mathrm{G}}, \mathrm{T}\right] \leq\left(\mathrm{U}_{\mathrm{i}-1}\right)_{\mathrm{G}}$. By Lemma $8\left(\mathrm{U}_{\mathrm{i}}\right)_{\mathrm{G}} /\left(\mathrm{U}_{\mathrm{i}-1}\right)_{\mathrm{G}}$ is torsion-free abelian. Similarly if $\mathrm{U}_{\mathrm{i}} / \mathrm{U}_{\mathrm{i}-1} \in \mathbf{X}$, then $\left(\mathrm{U}_{\mathrm{i}}\right)_{\mathrm{G}} /\left(\mathrm{U}_{\mathrm{i}-1}\right)_{\mathrm{G}} \in \mathbf{X}$. Thus the series $\left\{\left(\mathrm{U}_{\mathrm{i}}\right)_{\mathrm{G}}, \mathrm{i}=1,2, \ldots\right\}$ also satisfies $(*)$. Further if $\mathbf{X}=\mathbf{X}_{\mathrm{mm}}$ and $\left[\mathrm{U}_{\mathrm{i}}, \mathrm{T}\right]$ is not contained in $\mathrm{U}_{\mathrm{i}-1}$, then $\mathrm{T} / \mathrm{C}_{\mathrm{T}}\left(\mathrm{U}_{\mathrm{i}} / \mathrm{U}_{\mathrm{i}-1}\right)$ is finitely generated and abelian (since $\mathrm{T} / \mathrm{U}$ is abelian). It follows that $\mathrm{T} / \mathrm{C}_{\mathrm{T}}\left(\left(\mathrm{U}_{\mathrm{i}}\right)_{\mathrm{G}} /\left(\mathrm{U}_{\mathrm{i}-1}\right)_{\mathrm{G}}\right)$ is also finitely generated and abelian (Lemma 8 again). Hence to simplify notation assume we have already chosen the $U_{i}$ to satisfy (*) with all $\mathrm{U}_{\mathrm{i}}$ normal in $\mathrm{G}$. 
If $\mathrm{U}_{\mathrm{i}} / \mathrm{U}_{\mathrm{i}-1} \in \mathbf{X}$, set $\mathrm{V}_{\mathrm{i}}=\mathrm{U}_{\mathrm{i}}$. Suppose $\left[\mathrm{U}_{\mathrm{i}}, \mathrm{T}\right] \leq \mathrm{U}_{\mathrm{i}-1}$. If $\mathbf{X}=\mathbf{X}_{\mathrm{fr}}$ or $\mathbf{X}_{\mathrm{mm}}$, then $\mathrm{G} / \mathrm{U}_{\mathrm{i}-1}$ is $\mathbf{X}$-Engel and so by Lemma 5 there exists a normal subgroup $V_{i}$ of $G$ with $U_{i-1} \leq V_{i} \leq U_{i}$, with $\mathrm{V}_{\mathrm{i}} / \mathrm{U}_{\mathrm{i}-1} \in \mathbf{X}$ and with $\mathrm{U}_{\mathrm{i}} / \mathrm{V}_{\mathrm{i}}$ G-hypercentral. Let $\mathbf{X}=\mathbf{X}_{\mathrm{ftr}}$. Now a torsion-free abelian group in $\mathbf{X}_{\mathrm{fr}}$ is also in $\mathbf{X}_{\mathrm{ftr}}, \mathbf{X}_{\mathrm{ftr}} \subseteq \mathbf{X}_{\mathrm{fr}}$ and $\mathrm{U}_{\mathrm{i}} / \mathrm{U}_{\mathrm{i}-1}$ is torsion-free abelian. Thus by the $\mathbf{X}_{\mathrm{fr}}$ case there exists a normal subgroup $\mathrm{V}_{\mathrm{i}}$ of $\mathrm{G}$ with $\mathrm{U}_{\mathrm{i}-1} \leq \mathrm{V}_{\mathrm{i}} \leq \mathrm{U}_{\mathrm{i}}$, with $\mathrm{V}_{\mathrm{i}} / \mathrm{U}_{\mathrm{i}-1} \in \mathbf{X}$ and with $\mathrm{U}_{\mathrm{i}} / \mathrm{V}_{\mathrm{i}}$ G-hypercentral. Finally if $\mathbf{X}$ is $\mathbf{X}_{\mathrm{fr}}$ or $\mathbf{X}_{\mathrm{mm}}$ we can also apply Lemma 5 to $\mathrm{T} / \mathrm{U} \leq \mathrm{G} / \mathrm{U}$. Hence in these cases (and using [2] and [3] again) there is a normal $\mathbf{X}$-subgroup S/U of $\mathrm{G} / \mathrm{U}$ with G/S hypercentral. The proof of the proposition is complete (since $\mathbf{X}_{\mathrm{ftr}} \subseteq \mathbf{X}_{\mathrm{fr}}$ ).

Remark Note that Theorem 2 follows from Proposition 2. For the proof of Lemma 7 all we need of the class $\mathbf{X}$ is that $\mathbf{X}=\mathrm{S} \mathbf{X} \subseteq \mathbf{X}_{\mathrm{fr}}$ and that whenever B a torsion-free abelian group, $\mathrm{E}$ an $\mathbf{X}$-subgroup of $\mathrm{B}$ and $\phi$ is an monomorphism of $\mathrm{B}$ into itself with $\mathrm{E} \phi \leq \mathrm{E}$, then $\bigcup_{\mathrm{i} \geq 1} E \phi^{-\mathrm{i}} \in \mathbf{X}$. Note that the latter condition holds if also $\mathbf{X}_{\mathrm{fr}} \cap L \mathbf{X}=\mathbf{X}$. Further the proof of Proposition 2 is valid if $\mathbf{X}$ satisfies these conditions for Lemma 7 to hold and also satisfies $\mathbf{X}=\mathbf{Q X}=\mathbf{P X}=\mathbf{X F}$.

For any group $\mathrm{G}$ denote the lower central series of $\mathrm{G}$ by $\left\{\gamma^{\mathrm{i}} \mathrm{G}: \mathrm{i} \geq 1\right\}$.

Lemma 9 Let $\mathbf{X}$ be a class of groups which contains every homomorphic image of the tensor product of any two abelian $\mathbf{X}$-groups. If $\mathrm{G}$ is a group with a central subgroup $\mathrm{Z}$ such that $\mathrm{G} / \mathrm{G}^{\prime} \mathrm{Z} \in \mathbf{X}$, then $\gamma^{\mathrm{i}} \mathrm{G} / \gamma^{\mathrm{i}+1} \mathrm{G} \in \mathbf{X}$ for every integer $\mathrm{i} \geq 2$. In particular if $\mathrm{G}$ is nilpotent, then $\mathrm{G}^{\prime} \in \mathrm{PX}$.

Proof If $\mathrm{Z}=<1>$, this is 2.26 of [6] and a very small modification of its proof (or alternatively of the proof of $b$ ) on Page 10 of [11]) will produce a proof of Lemma 9.

Lemma 10 Let $\mathrm{A}_{1}$ and $\mathrm{A}_{2}$ be abelian groups and denote the tensor product of $\mathrm{A}_{1}$ and $\mathrm{A}_{2}$ by $\mathrm{T}$.

(i) If each $\mathrm{A}_{\mathrm{i}}$ can be generated by $\mathrm{r}_{\mathrm{i}}<\infty$ elements then $\mathrm{T}$ can be generated by at most $\mathrm{r}_{1} \mathrm{r}_{2}$ elements.

(ii) If rankA $\mathrm{A}_{\mathrm{i}}=\mathrm{r}_{\mathrm{i}}$ for each $\mathrm{i}$, then $\operatorname{rankT} \leq \mathrm{r}_{1} \mathrm{r}_{2}$.

(iii) If $\mathrm{A}_{1}$ and $\mathrm{A}_{2}$ are minimax, then so is $\mathrm{T}$.

Proof (i) is obvious and (ii) follows easily from it. For (iii) if each $A_{i}$ is minimax, there are finitely generated subgroups $\mathrm{B}_{\mathrm{i}}$ of $\mathrm{A}_{\mathrm{i}}$ with $\mathrm{C}_{\mathrm{i}}=\mathrm{A}_{\mathrm{i}} / \mathrm{B}_{\mathrm{i}}$ divisible, abelian and Chernikov ([6] 10.31). The tensor product of $C_{1}$ and $C_{2}$ is $<0>$ by (D) of Section 59 of [4] and the tensor product $\mathrm{T}_{\mathrm{ij}}$ of $\mathrm{A}_{\mathrm{i}}$ and $\mathrm{B}_{\mathrm{j}}$ is minimax, being a direct sum of finitely many copies of images of $A_{i}$, ibid. $(H)$ and (I). Thus the tensor product of the exact sequences

$$
\mathrm{B}_{\mathrm{i}} \rightarrow \mathrm{A}_{\mathrm{i}} \rightarrow \mathrm{C}_{\mathrm{i}} \rightarrow 0, \quad \mathrm{i}=1,2
$$

([4] 60.3) yields that $\mathrm{T}$ is an image of $\mathrm{T}_{12} \oplus \mathrm{T}_{21}$ and as such is minimax.

Lemma 11 Let $\mathrm{N}$ be a subgroup of the group $\mathrm{G}$ and $\mathrm{g}$ an element of $\mathrm{G}$ with $\mathrm{N}^{\mathrm{g}} \leq \mathrm{N}$. Set $\mathrm{M}=\mathrm{N}^{<\mathrm{g}>}$. If $\mathrm{N}$ has finite rank, then so does $\mathrm{M}$. If $\mathrm{N}$ is soluble and minimax, then so is $\mathrm{M}$.

Proof Clearly $\mathrm{g}^{-(\mathrm{i}+1)} \mathrm{Ng}^{\mathrm{i}+1} \leq \mathrm{g}^{-\mathrm{i}} \mathrm{Ng}^{\mathrm{i}}$ for each integer i, so $\mathrm{M}=\bigcup_{\mathrm{i}} \mathrm{g}^{-\mathrm{i}} \mathrm{Ng}^{\mathrm{i}}$. If $\mathrm{X}$ is a finitely generated subgroup of $\mathrm{M}$, then $\mathrm{X} \cong \mathrm{g}^{-\mathrm{i}} \mathrm{Xg}^{\mathrm{i}} \leq \mathrm{N}$ for some $\mathrm{i}$, so rankM=rankN. Suppose $\mathrm{N}$ is soluble and minimax. Clearly then $\mathrm{M}$ is soluble (with the same derived length as $\mathrm{N}$ ). 
Suppose $\mathrm{M}$ is abelian. Now $\mathrm{N}^{\mathrm{g}} \cong \mathrm{N}, \mathrm{N}^{\mathrm{g}} \leq \mathrm{N}$ and $\mathrm{N}$ is abelian and minimax. Hence $\mathrm{N} / \mathrm{N}^{\mathrm{g}}$ is periodic and Chernikov. In particular $\mathrm{N} / \mathrm{N}^{\mathrm{g}}$ is a $\pi$-group for some finite set $\pi$ of primes. Clearly $\mathrm{g}^{-\mathrm{i}} \mathrm{Ng}^{\mathrm{i}} / \mathrm{g}^{-(\mathrm{i}+1)} \mathrm{Ng}^{\mathrm{i}+1} \cong \mathrm{N} / \mathrm{N}^{\mathrm{g}}$ for each i. Consequently $\mathrm{M} / \mathrm{N}$ is a $\pi$-group. It also has finite rank, since $\mathrm{M}$ does by the first part. Therefore $\mathrm{M} / \mathrm{N}$ is Chernikov. Also $\mathrm{N}$ is minimax. Hence so is M. In general

$$
\mathrm{M}^{\prime}=\mathrm{U}_{\mathrm{i}}\left(\mathrm{g}^{-\mathrm{i}} \mathrm{Ng} \mathrm{g}^{\mathrm{i}}\right)^{\prime}=\mathrm{U}_{\mathrm{i}} \mathrm{g}^{-\mathrm{i}} \mathrm{N}^{\prime} \mathrm{g}^{\mathrm{i}} \text { and } \mathrm{g}^{-1} \mathrm{~N}^{\prime} \mathrm{g}=\left(\mathrm{N}^{\mathrm{g}}\right)^{\prime} \leq \mathrm{N}^{\prime} .
$$

By induction on the derived length of $\mathrm{M}$ we may assume that $\mathrm{M}^{\prime}$ is minimax and by the abelian case above $\mathrm{M} / \mathrm{M}^{\prime}$ is minimax. Consequently $\mathrm{M}$ is minimax.

Proposition 3 Let $<1>=\mathrm{U}_{0} \leq \mathrm{U}_{1} \leq \cdots \leq \mathrm{U}_{\mathrm{t}}=\mathrm{U} \leq \mathrm{T}$ be a normal series of the group $\mathrm{T}$ with $\mathrm{t}$ finite, $\mathrm{T} / \mathrm{U}$ abelian and for all $\mathrm{i}$ we have $\left[\mathrm{U}_{\mathrm{i}}, \mathrm{U}\right] \leq \mathrm{U}_{\mathrm{i}-1}$ and either $\mathrm{U}_{\mathrm{i}} / \mathrm{U}_{\mathrm{i}-1} \in \mathbf{X}$ or $\left[\mathrm{U}_{\mathrm{i}}\right.$, $\mathrm{T}] \leq \mathrm{U}_{\mathrm{i}-1}$, for $\mathbf{X}$ some class of groups.

(i) If $\mathbf{X}$ is $\mathbf{X}_{\mathrm{fr}}$ or $\mathbf{X}_{\mathrm{mm}}$, then $\mathrm{T}$ is $\mathbf{X}$-Engel.

(ii) If $\mathrm{U}$ is torsion-free and $\mathbf{X}=\mathbf{X}_{\mathrm{ftr}}$, then again $\mathrm{T}$ is $\mathbf{X}$-Engel.

Proof (i) Now T/U is abelian and hence Engel. Thus by induction on t we may assume that $\mathrm{T} / \mathrm{U}_{1}$ is $\mathbf{X}$-Engel. Since $\mathbf{P X}=\mathbf{X}$, if $\mathrm{U}_{1} \in \mathbf{X}$, then $\mathrm{T}$ is also $\mathbf{X}$-Engel. Henceforth assume that $\left[\mathrm{U}_{1}, \mathrm{~T}\right]=<1>$.

Let $\mathrm{g} \in \mathrm{T}$. There exists a g-sink $\mathrm{X} / \mathrm{U}_{1} \in \mathbf{X}$ in $\mathrm{T} / \mathrm{U}_{1}$. Clearly we may pick $\mathrm{X}$ in $\mathrm{U}$. For all $\mathrm{x}$ in $\mathrm{T}$ there exists $\mathrm{m}(\mathrm{x})$ with $\left[\mathrm{x},{ }_{\mathrm{n}} \mathrm{g}\right] \in X$ for all $\mathrm{n} \geq \mathrm{m}(\mathrm{x})$. We may assume that $\mathrm{X}=<\left[\mathrm{x},{ }_{\mathrm{n}} \mathrm{g}\right]$ : $x \in T, n \geq m(x)>U_{1}$. Since $\left[x,{ }_{n} g\right]^{g}=\left[x,{ }_{n} g\right]\left[x,{ }_{n+1} g\right]$ we have $X^{g} \leq X$. Set $Y=X^{<g>}$. Then $\mathrm{U}_{1} \leq \mathrm{Y} \leq \mathrm{U}, \mathrm{U}$ is nilpotent and $\mathrm{Y} / \mathrm{U}_{1} \in \mathbf{X}$ by Lemma 11 . Clearly $\mathrm{Y} / \mathrm{U}_{1}$ is also a g-sink in $\mathrm{T} /$ $\mathrm{U}_{1}$.

Now $\mathrm{Y}^{\prime} \in \mathbf{X}$ by Lemmas 9 and 10 . Suppose $\mathrm{Y}^{\prime}=<1>$. Then $[\mathrm{Y}, \mathrm{g}] \cong \mathrm{Y} / \mathrm{C}_{\mathrm{Y}}(\mathrm{g})$ and $\mathrm{C}_{\mathrm{Y}}(\mathrm{g}) \geq \mathrm{U}_{1}$. Hence $[\mathrm{Y}, \mathrm{g}] \in \mathbf{X}$ and clearly it is a g-sink in $\mathrm{Y}$. In general this shows that $[\mathrm{Y}, \mathrm{g}]$ $\mathrm{Y}^{\prime}$ is a $\mathrm{g}$-sink in $\mathrm{Y}$ and hence in $\mathrm{G}$. Further $[\mathrm{Y}, \mathrm{g}] \mathrm{Y}^{\prime}$ lies in $\mathbf{X}$ since $\mathbf{P X}=\mathbf{X}$. This completes the proof of (i).

(ii) Here $\mathbf{X}=\mathbf{X}_{\mathrm{ftr}} \subseteq \mathbf{X}_{\mathrm{fr}}$, so if $\mathrm{g} \in \mathrm{T}$ there is a $\mathrm{g}$-sink $\mathrm{X}$ in $\mathrm{T}$ with $\mathrm{U} \geq \mathrm{X} \in \mathbf{X}_{\mathrm{fr}}$. But then $\mathrm{X}$ is torsion-free (as $\mathrm{U}$ here is by hypothesis) and nilpotent, so its upper central factors are torsion-free of finite rank and hence $\mathrm{X} \in \mathbf{X}_{\mathrm{ftr}}$. Consequently $\mathrm{T}$ is $\mathbf{X}$-Engel.

Proof of Theorem 3 If $\mathrm{G}$ in Theorem 3 is $\mathbf{X}$-Engel, apply Proposition 2 with T taken to be $\mathrm{G}$ itself. Conversely if $\mathrm{G}$ has a series as in Theorem 3, then $\mathrm{G}$ is soluble, connected and so triangularizable. Then $\mathrm{G}^{\prime}$ is unipotent and hence torsion-free. Replacing each $\mathrm{U}_{\mathrm{i}}$ by $\mathrm{G}^{\prime} \cap \mathrm{U}_{\mathrm{i}}$ produces a series with the same properties as given in the theorem but now with $U$ torsionfree (note that $\mathbf{X}$ is subgroup closed). Thus $\mathrm{G}$ is $\mathbf{X}$-Engel by Proposition 3.

Proof of the Corollary If $\mathrm{G}$ has a normal $\mathbf{X}$-Engel subgroup $\mathrm{T}$ of finite index, then $\mathrm{T}^{\mathrm{o}}$ is a connected normal $\mathbf{X}$-Engel subgroup of $\mathrm{G}$ of finite index. Now $\mathrm{T}^{\mathrm{o}}$ has a normal series as in Theorem 3, which gives a series for $\mathrm{G}$ of the required type. If $\mathrm{G}$ has a series as in the Corollary, then $\mathrm{T}^{\mathrm{o}}$ is $\mathbf{X}$-Engel by Theorem 3 and $\mathrm{G}$ is (X-Engel)-by-finite.

Proof of Theorem 4 First suppose $\mathrm{Q}$ is a torsion-free normal subgroup of an LF-Engel group $R$. If $g \in R$ there is a $g$-sink $X \in L F$ in $R$. If $x \in Q$ there exists $m \geq 1$ with $\left[x,{ }_{m} g\right.$ ] $\in X \cap Q=<1>$. Therefore $Q$ consists of right Engel elements of $R$. In particular if either $R$ is linear or $\mathrm{Q}$ is abelian with $\mathrm{R} / \mathrm{C}_{\mathrm{R}}(\mathrm{Q})$ finite, then $\mathrm{Q} \leq \zeta(\mathrm{R})$, see [9] 8.15 and 8.1. 
Suppose the group G in the theorem is LF-Engel. Then G is soluble-by-finite by Lemma 2. Hence $G$ has a triangularizable normal subgroup $T$ of finite index. By the previous paragraph $\mathrm{u}(\mathrm{T}) \leq \zeta(\mathrm{G})$ and $\mathrm{T} / \mathrm{u}(\mathrm{T})$ is abelian. Thus $\mathrm{T}$ is locally nilpotent. It now suffices to consider just two cases, the case where $\mathrm{T}$ is unipotent and the case where $\mathrm{T}$ is diagonalizable, see Remark 3.3 of [14].

Set $S=\tau(T)$. If $T$ is unipotent, then $S=<1>$ and $T \leq \zeta(\mathrm{G})$ by the above. If $\mathrm{T}$ is diagonalizable, then $\mathrm{G} / \mathrm{C}_{\mathrm{G}}(\mathrm{T})$ is finite ([9] 1.12). Also T/S is abelian and torsion-free. Consequently $\mathrm{T} / \mathrm{S} \leq \zeta(\mathrm{G} / \mathrm{S})$. Thus $(\mathrm{G} / \mathrm{S}: \zeta(\mathrm{G} / \mathrm{S}))$ is finite in both cases, so there exists a finite normal subgroup $\mathrm{N} / \mathrm{S}$ of $\mathrm{G} / \mathrm{S}$ with $\mathrm{G} / \mathrm{N}$ hypercental ([3]). Clearly $\mathrm{N}$ is locally finite. Conversely any group with such a normal subgroup is LF-Engel.

Open Access This article is licensed under a Creative Commons Attribution 4.0 International License, which permits use, sharing, adaptation, distribution and reproduction in any medium or format, as long as you give appropriate credit to the original author(s) and the source, provide a link to the Creative Commons licence, and indicate if changes were made. The images or other third party material in this article are included in the article's Creative Commons licence, unless indicated otherwise in a credit line to the material. If material is not included in the article's Creative Commons licence and your intended use is not permitted by statutory regulation or exceeds the permitted use, you will need to obtain permission directly from the copyright holder. To view a copy of this licence, visit http://creativecommons.org/licenses/by/4.0/.

\section{References}

1. Carter, R.W.: Simple Groups of Lie Type. Wiley, London (1972)

2. Casolo, C., Dardano, U., Rinauro, S.: Variants of theorems of Baer and Hall on finite-by-hypercentral groups. J. Algebra 452, 279-287 (2016)

3. de Falco, M., de Giovanni, F., Musella, C., Sysak, Y.P.: On the upper central series of infinite groups. Proc. Am. Math. Soc. 139, 385-389 (2011)

4. Fuchs, L.: Infinite Abelian Groups, vol. 1. Academic Press, New York (1970)

5. Lennox, J.C., Robinson, D.J.S.: The Theory of Infinite Soluble Groups. Clarendon Press, Oxford (2004)

6. Robinson, D.J.S.: Finiteness Conditions and Generalized Soluble Groups, vol. 2. Springer, Berlin (1972)

7. Samuel, P.: A propos du théorème des unités. Bull. Sci. Math. 90, 89-96 (1966)

8. Shumyatsky, P.: Almost Engel linear groups. Monatsh. Math. 186, 711-719 (2018)

9. Wehrfritz, B.A.F.: Infinite Linear Groups. Springer, Berlin (1973)

10. Wehrfritz, B.A.F.: Periodic normal subgroups of linear groups. Arch. Math. 71, 169-172 (1998)

11. Wehrfritz, B.A.F.: Group and Ring Theoretic Properties of Polycyclic Groups. Springer, London (2009)

12. Wehrfritz, B.A.F.: Almost fixed-point-free automorphisms of prime order. Cent. Eur. J. Math. 9, 616626 (2011)

13. Wehrfritz, B.A.F.: Variants of theorems of Schur, Baer and Hall. Ric. Mat. 67, 331-337 (2018)

14. Wehrfritz, B.A.F.: Weak Engel conditions on linear groups. Adv. Group Theory Appl. 7, 143-157 (2019)

15. Wehrfritz, B.A.F.: The structure of linear PF-Engel groups in characteristic zero. Boll. Unione Mat. Ital. (2019). https://doi.org/10.1007/s40574-019-00197-6

Publisher's Note Springer Nature remains neutral with regard to jurisdictional claims in published maps and institutional affiliations. 